\title{
Borderline Health: Potential Risks to Patients and Practitioners of Jurisdictional Variation in Australian Medicines Legislation
}

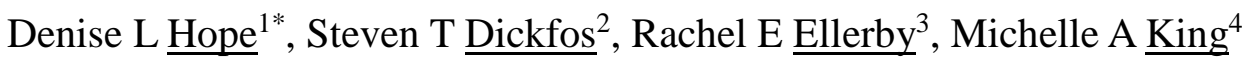

${ }^{1}$ BPharm, MMedRes, GradCertHigherEd; Lecturer, School of Pharmacy, Griffith University, Queensland, Australia

${ }^{2}$ BSc (Oceanography), BPharmaceutSci, MPharm; Flight Lieutenant, Royal Australian Air Force (RAAF), Canberra, Australia

${ }^{3}$ BPharmaceutSci, MPharm; Pharmacist, Miami Amcal Chempro Chemist, Queensland, Australia

${ }^{4}$ BPharm, PhD (Med); Senior Lecturer, Griffith Health Institute and School of Pharmacy, Griffith University, Queensland, Australia

\section{*Corresponding author.}

Denise L Hope

Tel.: +61 0755527339 Fax: +6107555 28804

E-mail address: d.hope@griffith.edu.au

Postal address: School of Pharmacy, Clinical Sciences 2, G16_3.26, Gold Coast Campus, Griffith University, QLD 4222, Australia

\section{Abstract: 145 words}




\title{
Main text: 1871 words
}

\section{Borderline Health: Jurisdictional Variation in Australian Medicines Legislation Poses Potential Risks to Patients and Healthcare Practitioners}

\begin{abstract}
Background Medicare and the Pharmaceutical Benefits Scheme may suggest to patients that medicines supply is the same everywhere in Australia. National Registration of Health Practitioners removed barriers to practitioners working interstate.
\end{abstract}
Aim To identify variations in state and territory medicines legislation with potential to negatively impact patients or practitioners.

Method Australian state and territory Acts and Regulations related to medicines prescribing and provision were compared. Legislative variations with potential to either harm patients, or increase health practitioners’ legal or ethical risk, were identified.

Results Potential patient harm may occur due to inconsistent requirements for prescription particulars, retention of prescription repeats by pharmacies in some states, or variation in age restriction on medicines provision.

Potential practitioner risk may arise due to inconsistencies in practitioners' prescribing rights or variable requirements to prescribe or dispense medicines.

Conclusion Ideally, all Australian states and territories should adopt uniform medicines legislation. 


\section{INTRODUCTION}

Australians are on the move. In the year 2013-2014 over 349,000 people moved interstate. In the most recent financial year there were an estimated 27 million interstate journeys with overnight stays. ${ }^{1}$ When Australians have experienced nationalised elements of the health system, e.g. through use of a Medicare Card, presentation of a Pharmaceutical Benefits Scheme (PBS) prescription, or purchase of an over the counter medicine they may erroneously assume that the supply of medicines is the same everywhere in Australia.

Australian health regulation evolved at a predominantly state level. ${ }^{2}$ Significant nationalisations of the health system occurred with the implementation of the Pharmaceutical Benefits Scheme in $1960^{3}$ and the introduction of Medibank in $1974 .{ }^{2}$ Currently, the Australian Federal Government oversees the national aspects of health policy, including the PBS and Medicare (a revised version of Medibank), with key elements (such as the operation of hospitals) operated by state governments. ${ }^{4}$

In 1986, Australia introduced national classification of medicines with implementation of the Standard for the Uniform Scheduling of Drugs and Poisons (SUSDP). ${ }^{5}$ This was renamed the Standard for the Uniform Scheduling of Medicines and Poisons (SUSMP) in July 2010, and is subordinate to the Therapeutic Goods Act $1989 .{ }^{6}$ The SUSDP was, and the SUSMP is, known as the Poisons Standard. ${ }^{7}$ Despite the national classification of medicines, the majority of drugs and poisons legislation remains state and territory-based because "jurisdictional differences have arisen over time, largely because of the way in which separate drugs and poisons legislation has developed”. ${ }^{8}$

Medicines may be prescribed by members of six of the 14 health professions currently registered with the Australian Health Practitioner Regulation Agency: registered doctors, 
dentists and some midwives, optometrists, podiatrists and nurse practitioners. ${ }^{9}$ National registration of health practitioners, introduced in July $2010,{ }^{10}$ removed barriers to health practitioners working across state borders. With the ability to practise in any jurisdiction practitioners may find themselves lacking complete and thorough knowledge of each jurisdiction's unique legislative requirements as the complexity of legislation makes "staying up to date with the requirements in each jurisdiction” difficult and costly. ${ }^{8}$

The Commonwealth Government Review of Drugs, Poisons and Controlled Substances Legislation (Galbally Review 2000) recommended uniform national drugs, poisons and controlled substances legislation with alignment between primary and subordinate legislation. ${ }^{8}$ The review was accepted and supported by the Australian Health Ministers' Advisory Council, ${ }^{11}$ but as yet jurisdictional variation and complexity remain.

Medicines schedules are recommended on a national basis but each jurisdiction has their own subcategories of special scheduled medicines for which there are specific requirements for prescribing or dispensing. The names of these categories and the drugs within them, are inconsistent. ${ }^{12}$ For example, confusion associated with the subcategories of specified restricted (e.g. pseudoephedrine, anabolic steroids) and regulated restricted drugs (e.g. isotretinoin, clomiphene) in Queensland (Qld) has been identified. ${ }^{13}$ Bernaitis et al indicated that some Qld pharmacists may refuse to supply a legally valid interstate prescription, or supply medicines for which the interstate prescription is not valid, due to this confusion. ${ }^{13}$ The Galbally Review identified that it was "almost impossible” to conduct a comprehensive comparison of legislation given the complexity and scope of legislative frameworks and differences between jurisdictions. ${ }^{8}$ As a result, the Galbally Review narrowed their approach to manageable examples or general terms without direct reference to specific legislation, using the Poisons Standard as a point of reference. This study reflected Galbally's rationale 
and its aim was to identify variations in state and territory medicines legislation that have the potential to impact negatively on patients or practitioners.

\section{METHOD}

Australian drugs and poisons legislation was interrogated to identify variations in requirements for the prescribing and/or provision of scheduled medicines, as classified by the Commonwealth Poisons Standard. The medicines schedules comprise Schedule 2 (S2) Pharmacy Medicines, Schedule 3 (S3) Pharmacist Only Medicines, Schedule 4 (S4) Prescription Only Medicines and Schedule 8 (S8) Controlled Drugs. The legislative instruments reviewed were mainly state and territory Acts and Regulations, with certain ancillary documents investigated where relevant (Table 1).

Table 1. Legislation and Relevant Ancillary Documents

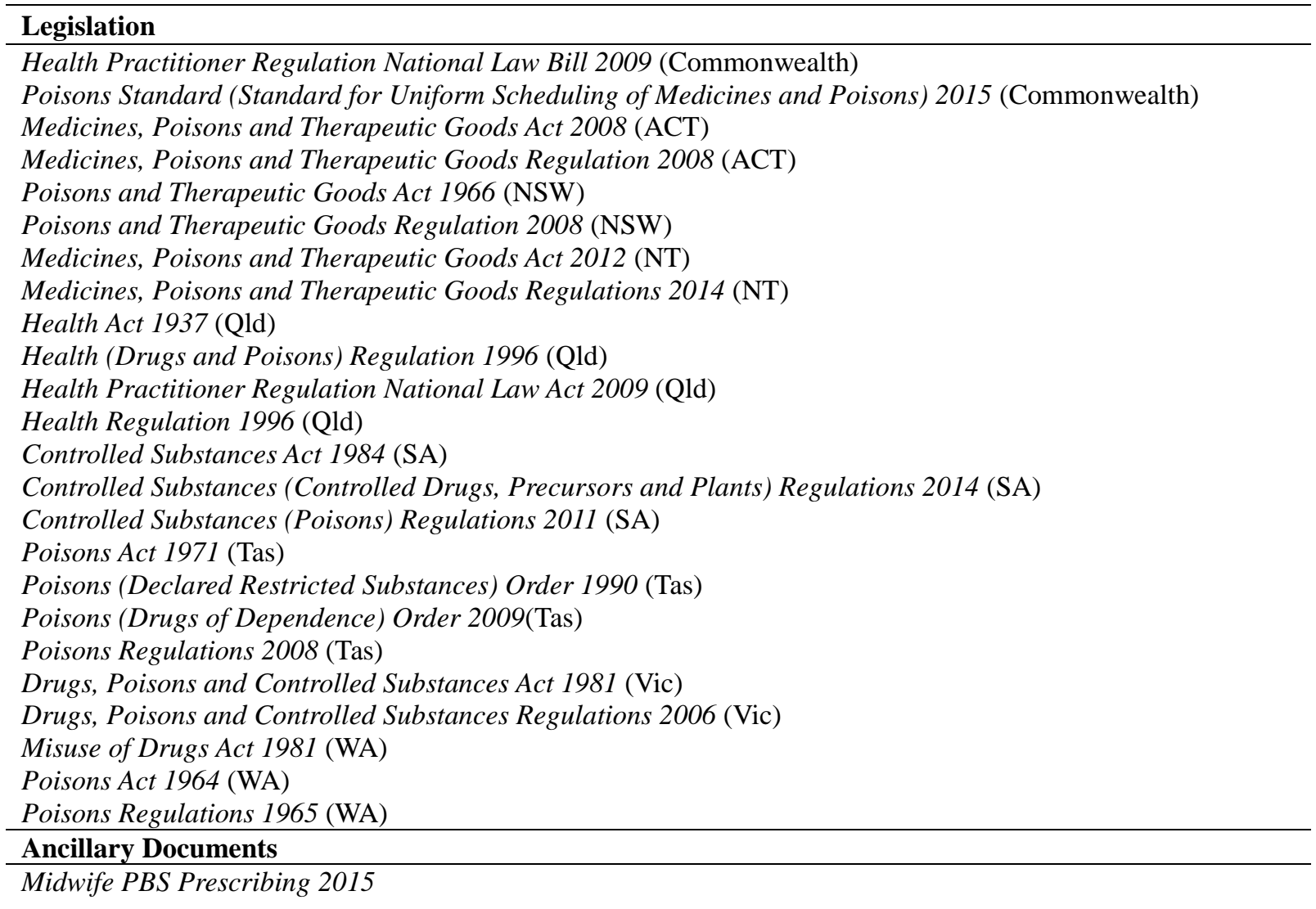


Podiatry Board of Australia Endorsement for Scheduled Medicines 2015

Prescribing Formulary for Eligible Midwives with a Scheduled Medicines Endorsement 2015

Professional Practice Standards Version 42010

Remote Health Atlas: Restricted Schedule 4 Medicines 2015 (NT)

A proof of concept study was conducted in 2013 by a research team of five Master of Pharmacy students, with two pharmacist supervisors. Researchers tabulated differences in the requirements for the prescription medicines schedules (S4 and S8) across jurisdictions. Comparisons were made of terminology and definitions; eligibility to prescribe; prescription inclusions, annotations and restrictions; consumers' access to medicines; dispensing requirements and restrictions; recording and retention of prescriptions; and storage and disposal requirements.

The initial research was confirmed and expanded to include all medicines schedules (S2, S3, S4 and S8) in 2014 and 2015. Due to the volume of legislative differences it was decided that those with the potential to either harm patients, or result in illegal or unethical practice by health practitioners, should be reported. Harm to patients was defined as any action that may delay medical treatment, reduce timely access to medicines, or cause physical or psychological damage. Legal and ethical health practitioner practice is defined and guided by legislation, policies, codes and guidelines, specific to each health profession. Variation in jurisdictional legislation was reported if it was considered to have the potential to disrupt a practitioner's legal and ethical conduct, whether deliberate or inadvertent. These determinations were based on the professional opinions of two authors and international literature. ${ }^{14,15}$ Professional opinions were guided by almost 60 years of combined pharmacy practice, which includes personal experience of patient concerns, complaints and adverse outcomes. 
Following determination of issues to be reported, all authors cross-checked and verified the findings, individually and collectively. Ethics approval was not required.

\section{RESULTS}

\section{Potential Harm to Patients}

Harm to patients, in the form of physical or psychological damage, or delayed access to medicines or medical treatment, may occur via a number of routes. For certain medicines and in certain jurisdictions, pharmacists may refuse to dispense due to inconsistent prescription requirements, or they may retain prescription repeats, or they may refuse to supply due to age restriction on medicines’ provision.

\section{Refusal to dispense due to inconsistent prescription requirements}

Prescription requirements vary across jurisdictions. States and territories are inconsistent regarding the specific details required on a prescription and the manner in which those details are presented, e.g. whether they need to be handwritten or require additional notation to be valid. Requirements for S8 Controlled Drugs vary most between jurisdictions. Additional S8 prescription details that are required in certain jurisdictions include:

- Patient's date of birth in NT, ${ }^{16}$ Qld, ${ }^{17}$ South Australia (SA) ${ }^{18}$ and WA; ${ }^{19}$

- Repeat interval in the Australian Capital Territory (ACT), ${ }^{20}$ New South Wales (NSW), ${ }^{21} \mathrm{NT},{ }^{16}$ Qld,${ }^{17}$ Tasmania (Tas) ${ }^{22}$ and WA $;{ }^{19}$

- Prescriber's qualifications in $\mathrm{ACT}^{20}$ and $\mathrm{Qld},{ }^{17}$ with $\mathrm{NT}^{16}$ requiring the health profession of the prescriber, rather than qualifications. Note: PBS prescription forms include prescriber qualifications; ${ }^{23}$ 
- Quantity in words and figures in $\mathrm{NSW},{ }^{21} \mathrm{NT},{ }^{16} \mathrm{Qld},{ }^{17} \mathrm{SA}^{18,24}$ and Vic; ${ }^{25}$ and

- Number of repeats in words and figures in Vic. ${ }^{25}$

Prescriptions valid in one state or territory may be invalid in others (Table 2). In the Northern Territory (NT), subject to Gazette notices, pharmacists may only dispense restricted S4 and S8 prescriptions if the prescriber works in the same state. ${ }^{26}$ Interstate prescriptions for restricted S4 medicines, which include benzodiazepines, pseudoephedrine, phenobarbitone and some analgesics, or interstate S8 prescriptions are therefore ineligible for supply in the NT. Similarly, Qld restricts dispensing of specified restricted (e.g. pseudoephedrine and anabolic steroids) and regulated restricted (e.g. isotretinoin and clomiphene) S4 medicines to prescribers with a Qld practice address. Therefore, interstate prescriptions for these medicines are invalid in Qld. In contrast to the NT however, Qld does allow the supply of interstate S8 prescriptions.

Table 2. Examples of Interstate Variation Affecting Medicines Provision

\begin{tabular}{|c|c|c|c|c|c|c|c|c|}
\hline & $\begin{array}{c}\mathrm{ACT} \\
20,27\end{array}$ & $\begin{array}{c}\text { NSW } \\
21,28\end{array}$ & $\begin{array}{l}\text { NT } \\
16,26\end{array}$ & $\begin{array}{c}\text { Qld } \\
17\end{array}$ & $\begin{array}{c}\text { SA } \\
18,29\end{array}$ & $\begin{array}{c}\text { Tas } \\
22,30\end{array}$ & $\begin{array}{l}\text { Vic } \\
25,31\end{array}$ & $\begin{array}{l}\text { WA } \\
19,32\end{array}$ \\
\hline \multicolumn{9}{|l|}{ Validity of Interstate $\mathbf{R x}$} \\
\hline S4 anabolic steroids & $\sqrt{ }$ & $\sqrt{ }$ & $\sqrt{\text { a }}$ & $x$ & $\sqrt{ }$ & $x$ & $\sqrt{ }$ & $\sqrt{ }$ \\
\hline S4 benzodiazepines & $\checkmark$ & $\checkmark$ & $\mathbf{x}_{b}$ & $\sqrt{ }$ & $\sqrt{ }$ & $x$ & $\checkmark$ & $\sqrt{ }$ \\
\hline S8 benzodiazepines & $\mathbf{x}_{\mathrm{c}}$ & $\sqrt{ }$ & $\mathbf{x}_{b}$ & $\sqrt{ }$ & $\sqrt{ }$ & $x$ & $\sqrt{ }$ & $\sqrt{ }$ \\
\hline S4 clomiphene & $\sqrt{ }$ & $\sqrt{\mathrm{d}}$ & $V_{\mathrm{a}}$ & $x$ & $\sqrt{ }$ & $\sqrt{ }$ & $\sqrt{ }$ e & $\checkmark$ \\
\hline S4 isotretinoin & $\sqrt{ }$ & $\sqrt{\mathrm{d}}$ & $\sqrt{\mathrm{a}}$ & $x$ & $\sqrt{ }$ & $\checkmark$ & $\sqrt{ }$ e & $\sqrt{ }$ \\
\hline S3/4 pseudoephedrine & $\sqrt{ }$ & $\sqrt{ }$ & $\mathbf{x}_{b}$ & $x$ & $\sqrt{ }$ & $x$ & $\sqrt{ }$ & $\checkmark$ \\
\hline S8 medicines & $\boldsymbol{x}_{\mathrm{c}}$ & $\sqrt{ }$ & $\mathbf{x}_{\mathrm{b}}$ & $\sqrt{ }$ & $V_{\mathrm{f}}$ & $x$ & $V_{\mathrm{f}}$ & $\sqrt{\mathrm{f}, \mathrm{g}}$ \\
\hline \multicolumn{9}{|l|}{ Retention of Repeats } \\
\hline S4 anabolic steroids & - & $\sqrt{ }$ & - & - & - & - & - & - \\
\hline S8 medicines & - & $\sqrt{ }$ & - & - & - & $\sqrt{ }$ & - & $\sqrt{ }$ \\
\hline \multicolumn{9}{|l|}{ S2/S3 Age Restriction } \\
\hline Only to persons $\geq 16$ years & - & - & - & $\sqrt{\mathrm{h}}$ & - & - & - & - \\
\hline \multicolumn{9}{|l|}{ S3 Medicines Provision } \\
\hline Requires recording of sale & $x$ & $x$ & $x$ & $\sqrt{\mathrm{i}}$ & $x$ & $x$ & $x$ & $\mathbf{x}_{j}$ \\
\hline
\end{tabular}


Requires labelling with patient-specific details

Requires therapeutic need

$\begin{array}{llllllll}\boldsymbol{x} & \boldsymbol{x} & \boldsymbol{x} & \boldsymbol{V} & \boldsymbol{V} & \boldsymbol{x} & \boldsymbol{x} & \boldsymbol{x} \\ \sqrt{1} & \boldsymbol{V} & \boldsymbol{x} & \sqrt{\mathrm{k}} & \boldsymbol{x} & \boldsymbol{V} & \boldsymbol{V} & \boldsymbol{V}\end{array}$

Pseudoephedrine Provision

Requires recording

Requires online accessible recording (Project STOP)

Requires photo identification

$\begin{array}{llll}\boldsymbol{V} & \boldsymbol{V} & \boldsymbol{V} & \boldsymbol{x} \\ \boldsymbol{V} & \boldsymbol{x} & \boldsymbol{V} & \boldsymbol{V}\end{array}$

$\begin{array}{lllll}\boldsymbol{V} & \boldsymbol{x} & \boldsymbol{x} & \boldsymbol{x} & \boldsymbol{V} \\ \boldsymbol{V} & \boldsymbol{V} & \boldsymbol{x} & \boldsymbol{x} & \boldsymbol{V}_{\mathrm{n}}\end{array}$

\section{Continued PBS Dispensing}

Without prescription

${ }^{a}$ Not specifically identified for exclusion in the NT Act or Regs.

${ }^{\mathrm{b}}$ Approval may be granted to a pharmacist to supply S8 and restricted S4 substances in certain circumstances.

$\mathrm{c}$ "The prescription for the controlled medicine cannot be dispensed in the ACT because the doctor is not registered in the ACT.” s121(3(b)1) Additionally, S8 prescriptions in ACT require prescriber approval in ACT.

${ }^{\mathrm{d}}$ Authority to prescribe is granted in NSW; prescriptions must be endorsed with the authority reference number.

e A warrant to prescribe is required in Victoria and the prescription must be endorsed with the warrant number.

${ }^{\mathrm{f}}$ Pharmacist must verify the bona fides of the prescription or supply 2 days of medicine only.

${ }^{\mathrm{g}}$ Except stimulants (e.g. dexamphetamine) and opioid pharmacotherapy (e.g. methadone).

${ }^{\mathrm{h}}$ Terbutaline and salbutamol inhalers are available to persons $>14$ years.

${ }^{\mathrm{i}}$ Must comply with quality standard; quality standard recommends recording details of the supply.

j Except pseudoephedrine and hydrocortisone.

${ }^{\mathrm{k}}$ Except pseudoephedrine, which requires unique ProjectSTOP identifier.

${ }^{1}$ Purpose to be consistent with "therapeutic standard" s7(1) (Act).

${ }^{\mathrm{m}}$ Other specified forms of identified accepted, e.g. birth certificate, seniors card.

${ }^{\mathrm{n}}$ Identification not required if person is known to the pharmacist.

- Not identified in legislation

\section{Retention of prescription repeats}

Medicines supply may be interrupted by the retention of S8 and some S4 prescriptions. In NSW, Tas $^{22}$ and WA, ${ }^{19}$ a pharmacist is required to retain a patient's prescription after dispensing any S8 medicine, whether or not the prescription has authorised repeats. The requirement for retention also applies to special restricted substances in NSW, which include anabolic steroids and some barbiturates. ${ }^{21}$

\section{Refusal of supply due to age restriction}

Age restrictions on the supply of non-prescription medicines are inconsistent. Queensland is the only Australian state to prohibit the sale of S2 or S3 medicines to persons under 16 years 
of age, or under 14 years in the case of salbutamol or terbutaline asthma inhalers. The national Poisons Standard classifies medicines such as adrenaline and emergency contraception (levonorgestrel) as S3, therefore a Qld pharmacist could not legally supply these medicines to a person under 16 without prescription.

\section{Potential Risk to Health Practitioners}

In contrast to patients being refused supply due to interstate differences in requirements for provision of certain medicines, practitioners unaware of jurisdictional variations may inadvertently prescribe, dispense or supply medicines in a way that contravenes the law. The eight state and territory jurisdictions have many variations in the requirements for prescribers.

\section{Potential Risk to Prescribers}

In Australia there are six categories of health practitioners with rights to prescribe. Registered doctors, dentists and nurse practitioners are able to prescribe S4 and S8 medicines in all jurisdictions (Table 3). The prescribing rights of midwives, optometrists and podiatrists vary based on the jurisdiction in which they practise. Prescribing rights may be limited to scope of practice and/or certain medicines. Section 94 of the Health Practitioner Regulation National Law is referred to in many state legislative instruments as providing the individual National Health Practitioner Boards power to define their own practitioners qualified to prescribe or supply scheduled medicines. ${ }^{33}$ There are situations when state legislation does not specifically define the prescribing rights of these practitioners, however National Boards for certain professions may define their own prescribing formulary for their qualified prescribers. Examples include the Prescribing Formulary for Eligible Midwives with a Scheduled Medicines Endorsement by the Nursing and Midwifery Board of Australia ${ }^{34}$ and Endorsement for Scheduled Medicines conferred by the Podiatry Board of Australia. ${ }^{35}$ 
Table 3. Jurisdictional Prescribing Eligibility

\begin{tabular}{|c|c|c|c|c|c|c|c|c|}
\hline & $\begin{array}{c}\text { ACT } \\
20,27\end{array}$ & $\begin{array}{c}\text { NSW } \\
21,28\end{array}$ & $\begin{array}{l}\mathrm{NT}^{\mathrm{a}} \\
16,26\end{array}$ & $\begin{array}{l}\text { Qld } \\
17\end{array}$ & $\begin{array}{c}\text { SA } \\
18,29\end{array}$ & $\begin{array}{c}\text { Tas } \\
22,30\end{array}$ & $\begin{array}{r}\text { Vic } \\
25,31\end{array}$ & $\begin{array}{l}\text { WA } \\
19,32\end{array}$ \\
\hline \multicolumn{9}{|l|}{ Prescriber type } \\
\hline Dentist - S4 & $\checkmark$ & $\checkmark$ & $\checkmark$ & $\checkmark$ & $\checkmark$ & $\checkmark$ & $\checkmark$ & $\checkmark$ \\
\hline Dentist - S8 & $\checkmark$ & $\checkmark$ & $\checkmark$ & $\checkmark$ & $\checkmark$ & $\checkmark$ & $\checkmark$ & $\checkmark$ \\
\hline Doctor - S4 & $\checkmark$ & $\checkmark$ & $\checkmark$ & $\checkmark$ & $\checkmark$ & $\checkmark$ & $\checkmark$ & $\checkmark$ \\
\hline Doctor - S8 & $\checkmark$ & $\checkmark$ & $\checkmark$ & $\checkmark$ & $\checkmark$ & $\checkmark$ & $\checkmark$ & $\checkmark$ \\
\hline Eligible midwife - S4 & $\checkmark$ & $\checkmark$ & $\checkmark$ & $\checkmark$ & $\sqrt{\mathrm{b}}$ & $\checkmark$ & $\checkmark$ & $\checkmark$ \\
\hline Eligible midwife - S8 & $\checkmark$ & $\checkmark$ & $\checkmark$ & $x$ & $\sqrt{\mathrm{b}}$ & $x$ & $\checkmark$ & $\checkmark_{\mathrm{c}}$ \\
\hline Nurse practitioner - S4 & $\checkmark$ & $\checkmark$ & $\checkmark$ & $\checkmark$ & $\checkmark$ & $\checkmark$ & $\checkmark$ & $\checkmark$ \\
\hline Nurse practitioner - S8 & $\checkmark$ & $\checkmark$ & $\checkmark$ & $\checkmark$ & $\checkmark$ & $\checkmark$ & $\checkmark$ & $\checkmark$ \\
\hline Optometrist - S4 & $x$ & $\checkmark$ & $\checkmark$ & $\checkmark$ & $x$ & $\checkmark$ & $\checkmark$ & $\checkmark$ \\
\hline Optometrist - S8 & $x$ & $x$ & $\checkmark$ & $x$ & $x$ & $x$ & $x$ & $x$ \\
\hline Podiatrist - S4 & $x$ & $\checkmark$ & $\checkmark$ & $\checkmark$ d & $\sqrt{\mathrm{b}}$ & $x$ & $\checkmark$ & $\checkmark$ \\
\hline Podiatrist - S8 & $x$ & $x$ & $\checkmark$ & $\sqrt{\mathrm{d}}$ & $\sqrt{\mathrm{b}}$ & $x$ & $x$ & $\checkmark$ \\
\hline
\end{tabular}

Note: prescribing rights in many jurisdictions are limited to scope of practice and/or certain medicines. In some jurisdictions prescribing rights are limited to authorised prescribers of a particular profession.

${ }^{a}$ Restricted S4 and Restricted S8 medicines must be prescribed by health practitioners practising (NT).

${ }^{\mathrm{b}}$ Practitioner is endorsed under section 94 of the Health Practitioner Regulation National Law (SA).

c Eligible midwife must administer the S8 medicine prescribed (WA).

${ }^{\mathrm{d}}$ Only surgical podiatrists (Qld).

Writing prescriptions that fail to comply with legislative requirements may result in the imposition of penalties in NSW, ${ }^{21,28} \mathrm{Qld},{ }^{17} \mathrm{SA},{ }^{18} \mathrm{Tas}^{22}$ and Vic. ${ }^{25}$ Fines are described as either a monetary penalty or penalty units. For example, Qld imposes 60 penalty units (corresponding to a maximum fine of \$7068 from 1 July 2015) ${ }^{36}$ for prescribing an S4 or S8 medicine in a way that does not comply with state regulations. ${ }^{17}$ The ACT, ${ }^{20,27} \mathrm{NT}^{16}$ and $\mathrm{WA}^{19}$ legislation do not describe a specific penalty for failing to write a prescription in the authorised way. 


\section{Potential Risk to Pharmacists}

Jurisdictional variation in drugs and poisons legislation has the potential to impact the legal or ethical practice of a pharmacist. Pharmacists practising in an unfamiliar jurisdiction may fail to recognise an invalid prescription or refuse to supply a valid prescription due to differences in legislative requirements (Table 2).

The supply of S3 medicines is highly regulated yet varies between jurisdictions (Table 2). Significant variations are associated with age restriction, recording, labelling and identification requirements for pseudoephedrine, some of which are associated with substantial penalties. For example, a pharmacist supplying pseudoephedrine in SA without: (1) appropriate photo identification, (2) recording of patient's details and (3) recording the transaction in Project STOP, could be liable for a $\$ 3000$ fine on each account. ${ }^{18}$ These requirements are not legislated in Tasmania or Victoria.

Continued Dispensing is the supply of an eligible medicine to a consumer under the PBS when there is an immediate need for that medicine but it is not practicable to obtain a prescription. ${ }^{37}$ Queensland is currently the only state that has not legislated continued dispensing (Table 2). Any pharmacist that has provided PBS medicines under this initiative elsewhere would practice illegally by doing so in Queensland. 


\section{DISCUSSION}

There is considerable variation in medicines legislation between jurisdictions which places patients and health practitioners at risk of harm. Despite more than a decade since the release of the Galbally Review ${ }^{8}$ little progress has been made towards uniform medicines legislation. Inconsistencies in legislation that have the potential to harm patients need urgent attention.

Interstate variation in requirements for a legal prescription may be a barrier to obtaining necessary medicines if travelling interstate. Patients may find that the valid prescription they have for their usual S4 or S8 medicine/s is unable to be dispensed in another state or territory. This potential complication was identified in a 2011 report on pharmaceutical drug misuse in Australia. ${ }^{38}$ For example, patients with chronic pain conditions or carers of children diagnosed with ADHD may take S8 prescriptions for regular opioid analgesics or psychostimulants on holidays, assuming they can be dispensed at any pharmacy in Australia. They may also be unaware of potential repercussions on medicines supply if remaining prescription repeats are retained by the dispensing pharmacy. If a patient is forced to see an unfamiliar doctor to maintain continuity of supply, it is unlikely that the prescriber would have access to their complete medical records and may suspect them of being a "doctorshopper”, the latter could result in offense to consumers or limited medicines provision. These medicines require an authority prescription for subsidy under the PBS, ${ }^{23}$ which further creates difficulties for a patient or prescriber if S8 authority repeats have been retained elsewhere.

Patients may also be refused access to non-prescription medicines. In Queensland, requests for emergency contraception, adrenaline auto-injectors and other S2 or S3 medicines can not be fulfilled to patients under 16 years of age. ${ }^{17}$ Age restrictions need to be supported by evidence that benefit is outweighed by harm and assessed in the context of other 
restrictions. ${ }^{15}$ In the case of emergency contraception, the World Health Organisation declares it safe for all women, including adolescents ${ }^{39}$ and a court ruling from the United States of America determined that age was not a valid reason for restricting the supply of emergency contraceptives. $^{15}$

Refusal to supply an S3 medicine can potentially cause patient and practitioner harm. This was exemplified by the 2013 death of a 14 year old patient in Ireland with acute anaphylaxis, who was denied provision of an adrenaline auto-injector by a law-abiding pharmacist. ${ }^{14}$ While pharmacists are required to supply medicines in accordance with the law, ${ }^{40}$ in a similar life-threatening situation a Queensland pharmacist would face a legal/ethical dilemma when considering the best interest of the patient.

Previous research conducted on Queensland pharmacists practising near a state border revealed that "lack of awareness of medicines legislation could translate to refusal of dispensing of otherwise legal prescriptions” for Regulated Controlled Drugs, potentially disrupting the continuum of patient care and bringing the profession into disrepute. ${ }^{13}$ Of legal concern is that the same study identified that "more than a third of all pharmacists surveyed would dispense an illegal interstate prescription for a Specified Restricted Drug (33.3\%) or a Regulated Restricted Drug (40.7\%)”. ${ }^{13}$ These risks are associated with dispensing of prescription medicines that may have specific subcategorisation or different handling requirements between states. A pharmacist that is used to practising in one jurisdiction is potentially at risk of breaching the law if they assume that a prescription that is legal in one state is going to be so in another.

Assuming that allied health practitioners have uniform prescribing rights across jurisdictions may also have negative consequences for the prescriber and dispensing pharmacist. Confusion may arise when a national formulary that includes S4 and S8 medicines is 
endorsed by the Board of a registered health profession, e.g. the National Podiatry Scheduled Medicines List, ${ }^{35}$ but individual state or territory legislation does not specifically confer prescribing rights to those practitioners. A similar situation exists for the Prescribing Formulary for Eligible Midwives. ${ }^{34}$ Items included in the formulary are also subsidised under the $\mathrm{PBS}^{41}$ yet only a portion of state legislation specifically allows eligible midwives to prescribe S8 Controlled Drugs. Prescribers crossing state lines must be cognisant of current legislation for the jurisdiction in which they intend to practise and prescribe, as it cannot be assumed that what was legal in one state is so in another.

The Galbally Review saw “no justification, in a country with a relatively small population and an even smaller industry base, for the costs of maintaining individual State and Territory legislation"” (Part B, p 156). Ideally, all states and territories should adopt uniform drugs, poisons and controlled substances legislation, with alignment between primary and subordinate legislation. ${ }^{8}$ However this complex task will take time and require commitment from all jurisdictions. National standardisation should commence with the Poisons Standard as a common reference point with a goal to align jurisdictional issues of subcategorisation, nomenclature and legislative requirements. ${ }^{8,12}$ At a state level, immediate attention should be paid to issues with the potential to impact patient care, in particular those raised in this paper.

In conclusion, variations in medicines legislation have the potential to cause patient harm, especially in relation to access to medicines for chronic conditions in situations where patients travel or move interstate. National registration removed barriers to interstate practice, however state and territory legislation governs medicines prescribing and provision. Ideally, medicines legislation should be uniform. Whenever medicines legislation is updated the opportunity to progress towards legislative harmony should be addressed. Meanwhile, the onus is on health practitioners to practise legally while ensuring optimal patient outcomes. 


\section{Acknowledgements}

Legislative instruments are regularly revised and updated. The authors referred to the most current legislation available at the time of the review.

The authors wish to acknowledge and thank Ms Jessica Bugg and colleagues for their assistance with this project.

\section{REFERENCES}

1. Australian Government Tourism Research Australia. Travel by Australians, June 2015. 2015;

http://www.tra.gov.au/documents/nvs/NVS_onepager_JUNE_2015_Final.pdf. Accessed 12 October 2015.

2. Griffith G. Commonwealth-State Responsibilities for Health: 'Big Bang' or Incremental Reform? : New South Wales Parliamentary Library Research Service; 2006.

3. Hattingh L, Low JS, Forrester K. Australian Pharmacy Law and Practice. Elsevier Health Sciences APAC; 2013.

4. Australian Government. Health. 2015; http://www.australia.gov.au/information-andservices/health. Accessed 12 October 2015.

5. National Health and Medical Research Council. Standard for the Uniform Scheduling of Drugs and Poisons No 1. In: Commonwealth Department of Health, ed. Canberra: Australian Government Publishing Service; 1986.

6. Therapeutic Goods Administration. The Therapeutic Goods Act 1989 and the Poisons Standard. 2015; https://www.tga.gov.au/therapeutic-goods-act-1989-poisons-standard. Accessed 12 October 2015. 
7. Therapeutic Goods Administration. Poisons Standard (Standard for Uniform Scheduling of Medicines and Poisons) No. 8. 2015;

https://www.comlaw.gov.au/Details/F2015L00844/Download. Accessed 12 October 2015.

8. Galbally R. National competition review of drugs, poisons and controlled substances legislation. Options paper. Canberra: Therapeutic Goods Administration 2000; http://www.tga.gov.au/archive/review-legislation-galbally-050628.htm\#final. Accessed 12 October 2015.

9. Australian Health Practitioner Regulation Agency. AHPRA - Regulating Australia's health practitioners in partnership with the National Boards. 2015; https://www.ahpra.gov.au/. Accessed 24 August 2015.

10. Australian Government. Health Practitioner Regulation National Law Bill 2009; https://www.legislation.qld.gov.au/Bills/53PDF/2009/HealPraRegNLB09Exp.pdf. Accessed 12 October 2015.

11. Australian Health Ministers' Advisory Council (AHMAC) Working Party. AHMAC Working Party response to the Review of Drugs, Poisons and Controlled Substances Legislation (the Galbally Review). 2003;

http://www.tga.gov.au/sites/default/files/review-galbally-050628-ahmac.pdf. Accessed 12 October 2015.

12. Hope DL, King MA. States of Confusion: Jurisdictional Variation in Australian Medicines Nomenclature. Journal of Law and Medicine. 2015;22:811-822.

13. Bernaitis NL, King MA, Hope DL. Interstate Dispensing: A Case for Uniform, Intuitive Legislation. Journal of Law and Medicine 2014;22:174-178.

14. Raidió Teilifís Éireann (RTE). Pharmaceutical Society of Ireland investigating death of teenager after peanut reaction. 2013; http://www.rte.ie/news/2013/1220/494102emma-sloan/. Accessed 12 October 2015.

15. Wood AJ, Drazen JM, Greene MF. The politics of emergency contraception. New England Journal of Medicine. 2012;366(2):101-102. 
16. Northern Territory of Australia. Medicines, Poisons and Therapeutic Goods Regulations 2014. 2014;

http://notes.nt.gov.au/dcm/legislat/legislat.nsf/2afcb7bfe1e1348e6925705a001697fb/c f32c6fe1eaa57d969257d0800261e56/\$FILE/Repm052R1.pdf. Accessed 12 October 2015.

17. Queensland Parliamentary Council. Health (Drugs and Poisons) Regulation 1996 2015;

https://www.legislation.qld.gov.au/LEGISLTN/CURRENT/H/HealDrAPoR96.pdf. Accessed 12 October 2015.

18. Government of South Australia. Controlled Substances (Poisons) Regulations 2011. 2013;

http://www.legislation.sa.gov.au/LZ/C/R/Controlled\%20Substances\%20(Poisons)\%20 Regulations\%202011.aspx. Accessed 12 October 2015.

19. Government of Western Australia. Poisons Regulations 1965. 2015;

http://www.slp.wa.gov.au/legislation/statutes.nsf/main_mrtitle_1920_homepage.html. Accessed 12 October 2015.

20. Australian Capital Territory Government. Medicines, Poisons and Therapeutic Goods Regulation 2008. 2015; http://www.legislation.act.gov.au/sl/2008-

42/current/pdf/2008-42.pdf. Accessed 12 October 2015.

21. New South Wales Government. Poisons and Therapeutic Goods Regulation 2008. 2015;

http://www.legislation.nsw.gov.au/viewtop/inforce/subordleg+392+2008+FIRST+0+ N/. Accessed 12 October 2015.

22. Tasmanian Government. Poisons Regulations 2008. 2015; http://www.thelaw.tas.gov.au/tocview/index.w3p;cond=;doc_id=\%2B162\%2B2008\% 2BAT\%40EN\%2B20151012150000;histon=;prompt=;rec=;term=. Accessed 12 October 2015.

23. Australian Government Department of Health. The Pharmaceutical Benefits Scheme (PBS). 2015; http://www.pbs.gov.au/pbs/home. Accessed 12 October 2015. 
24. Government of South Australia. Controlled Substances (Controlled Drugs, Precursors and Plants) Regulations 2014. 2015;

http://www.legislation.sa.gov.au/LZ/C/R/Controlled\%20Substances\%20(Controlled\% 20Drugs\%20Precursors\%20and\%20Plants)\%20Regulations\%202014.aspx. Accessed 12 October 2015.

25. Victorian Government. Drugs, Poisons and Controlled Substances Regulations 2006. 2015;

http://www.legislation.vic.gov.au/domino/Web_Notes/LDMS/LTObject_Store/ltobjst9 .nsf/DDE300B846EED9C7CA257616000A3571/181A16F743466397CA257ECF001 E0D66/\$FILE/06-57sra016\%20authorised.pdf. Accessed 12 October 2015.

26. Northern Territory of Australia. Medicines, Poisons and Therapeutic Goods Act 2012. 2014; http://www5.austlii.edu.au/au/legis/nt/consol_act/mpatga379/. Accessed 12 October 2015.

27. Australian Capital Territory Government. Medicines, Poisons and Therapeutic Goods Act 2008. 2015; http://www.legislation.act.gov.au/a/2008-26/current/pdf/2008-26.pdf. Accessed 12 October 2015.

28. New South Wales Government. Poisons and Therapeutic Goods Act 1966 2015; http://www.legislation.nsw.gov.au/viewtop/inforce/act+31+1966+FIRST+0+N/. Accessed 12 October 2015.

29. Government of South Australia. Controlled Substances Act 1984. 2014; http://www.legislation.sa.gov.au/LZ/C/A/CONTROLLED\%20SUBSTANCES\%20A CT\%201984.aspx. Accessed 12 October 2015.

30. Tasmanian Government. Poisons Act 1971. 2012;

http://www.thelaw.tas.gov.au/tocview/index.w3p;cond=;doc_id=81\%2B\%2B1971\%2 BAT\%40EN\%2B20151012150000;histon=;prompt=;rec=;term=. Accessed 12 October 2015.

31. Victorian Government. Drugs, Poisons and Controlled Substances Act 1981. 2014; http://www.legislation.vic.gov.au/domino/Web_Notes/LDMS/LTObject_Store/ltobjst9 
.nsf/DDE300B846EED9C7CA257616000A3571/96DB2149D82E1A00CA257D8700

0410B6/\$FILE/81-9719aa109A\%20authorised.pdf. Accessed 12 October 2015.

32. Government of Western Australia. Poisons Act 1964. 2014;

http://www.slp.wa.gov.au/legislation/statutes.nsf/main_mrtitle_728_homepage.html.

Accessed 12 October 2015.

33. Queensland Parliamentary Council. Health Practitioner Regulation National Law Act 2009; https://www.legislation.qld.gov.au/LEGISLTN/ACTS/2009/09AC045.pdf. Accessed 12 October 2015.

34. Nursing and Midwifery Board of Australia. Prescribing Formulary for Eligible Midwives with a Scheduled Medicines Endorsement. 2015;

http://www.nursingmidwiferyboard.gov.au/Registration-and-

Endorsement/Endorsements-Notations/Prescribing-Formulary.aspx. Accessed 12

October 2015.

35. Podiatry Board of Australia. Endorsement for Scheduled Medicines. 2015;

http://www.podiatryboard.gov.au/Registration-Endorsement/Endorsement-Scheduled-

Medicines.aspx. Accessed 12 October 2015.

36. Queensland Government. Sentencing fines and penalties for offences. 2015;

https://www.qld.gov.au/law/crime-and-police/types-of-crime/sentencing-fines-andpenalties-for-offences/. Accessed 12 October 2015.

37. Australian Government Department of Human Services. Continued dispensing of Pharmaceutical Benefits Scheme medicines in defined circumstances. 2015; http://www.humanservices.gov.au/health-professionals/services/fifth-communitypharmacy-agreement/continued-dispensing-of-pharmaceutical-benefits-schememedicines-in-defined-circumstances. Accessed 12 October 2015.

38. Nicholas R, Lee N, Roche A. Pharmaceutical drug misuse in Australia: Complex problems, balanced responses. National Centre for Education and Training on Addiction (NCETA), Flinders University, Adelaide. 2011.

39. World Health Organization. Fact sheet on the safety of levonorgestrel-alone emergency contraceptive pills (LNG ECPs). 2010; http://www.cecinfo.org/custom- 
content/uploads/2014/01/ICEC_WHO-Safety-Statement_2010-english.pdf. Accessed 12 October 2015.

40. Pharmaceutical Society of Australia. Professional Practice Standards - Version 4. 2010; http://www.psa.org.au/download/standards/professional-practice-standardsv4.pdf. Accessed 12 October 2015.

41. Australian Government Department of Health. Midwife PBS Prescribing. 2015; http://www.pbs.gov.au/browse/midwife. Accessed 12 October 2015. 